\title{
Using Google Docs to Improve Accuracy in Dialogue Writings
}

\author{
Michael Heath \\ The University of Manchester \\ United Kingdom
}

\begin{abstract}
In 2017, I set out to trial a new approach to teaching writing and speaking to a distance student learning online. This presentation will outline the development of a teaching plan which exploited the relatively new affordances that online tools such as Google docs TM and Microsoft Skydrive TM provide to teachers and students. I will begin by looking at the relative merits of synchronous (SCF) as opposed to asynchronous feedback (ACF) within the framework of a collaborative learning experience as key affordances offered by Google Docs TM, how effective this approach has proven to be, and how students report on their experiences of getting SCF during writing classes. More specifically, I will look at the merits of using Google Docs in collaborative dialogue building in an online distance one to one class. I'll look at how using this software allowed me to harness the benefits of collaborative writing and synchronous feedback to help a student improve language accuracy and awareness in small talk conversation through collaborative dialogue building tasks.
\end{abstract}

\section{Keywords—google docs; accuracy; writing}

\section{INTRODUCTION}

In this assignment, I will look at the merits of using Google Docs in collaborative dialogue building in an online distance one to one class. I'll look at how using this software can allow me to harness the benefits of collaborative writing and synchronous feedback to help a student improve language accuracy and awareness in small talk conversation through collaborative dialogue. I am currently teaching a private student one to on online. Both the student and I use a laptop and a tablet connected to the internet. The classes are run via SKYPE and I also use EDMODO as a place to communicate outside of the classroom. The student is a Russian speaker and works in the IT field. He's already proficient in English but displays a fair amount of fossilised inaccuracy and avoidance/overuse. He also has laboured pronunciation mainly due to sentence stress issues. He has lived and worked in Glasgow now for 14 years but still finds it difficult to engage in 'small talk' appropriately. Our agreed aims at the outset were to improve his confidence and ability to engage in conversation fluently and accurately. The latter was important to him as he felt his language ability caused him stress and was a barrier to conversational situations.

The format of the classes normally follows a test-teachtest structure with a key functional language focus such as extending the conversation or checking understanding. For instance, we take a small talk topic and engage in conversation, I'll take notes as we speak and, after we complete the conversation, there is time for language based feedback. This often centres around recasting and explicit correction of incorrect grammar, incorrect or inappropriate lexical choices and providing/eliciting alternative options. I'll then normally do some brainstorming around the central theme of the class, raising awareness of language options, meaning and use. After, we proceed to a new conversation task to implement the feedback. I provide a written feedback summary after the class to remind him of the key points and he also records the sessions so he can review them afterwards.

Although the student himself has said he found the approach useful, it became apparent to me that the feedback wasn't having as big impact I'd hoped for. Specifically, I hoped to iron out some of his more persistent grammatical errors (such as inappropriate and overuse of continuous forms), promote use of forms he avoided like perfect tenses, improve his pronunciation accuracy and expand the functional language options he has available during conversation. These typically improve over each class but re-deteriorate in the long term. To try and resolve this, in preparation for classes, I set him dialogue writing homework using conversational functional language using online resources to help him focus on language use. Unfortunately, this proved impractical as he didn't have much extra time outside of class. I had to find a solution which worked in class.

There are some key barriers when teaching conversational one to one classes. First of all, the teacher cannot disengage from the conversation, this makes it hard to consistently observe and address language issues. Secondly, as the discourse is spoken, it can be difficult for the student to remember and refer back to a specific utterance. This makes it hard to give feedback indirectly and allow the student to self-correct or choose which aspects of the language to focus on. In physical classrooms, I often make use of written examples/texts in order to facilitate conversations around language use, either presented on the board or as a text. Also, dialogue building has often been useful when I've wanted the students to focus on awareness of language accuracy, meaning and use. I've found that when we focus on producing dialogues, learners tend to 
transfer their oral speech patterns onto the written work and focus on spoken form outside of actual conversation. This has worked as a kind of rehearsal before speaking activities, and has usually had positive results in the classroom. Up until now. I hadn't been able to find a way to do this in one to one classes online. This idea initially caused me concern. Can focus on writing really help a student to improve language use in other areas like speaking? Reference [1] discusses the distinction between 'learning to write' and 'writing to learn'. When considering the latter, during collaborative writing, students can be seen to improve knowledge about language though conversation about the language which can lead to noticing and awareness of language features which helps other areas of language competence. In terms of online teaching this issue is even more acute. I became interested in google docs as a possible way to overcome these challenges recently, as it combines some of the useful features of a word processor with the ability to collaborate remotely and synchronously in real time on editing the content. Furthermore, it can be used as a permanent record for the student to refer to after the class for review.

\section{LITERATURE REVIEW}

Reference [2] describes programmes like Google Docs TM as "online simultaneous editing software". This kind of programme is a relatively recent tool to language teachers and offers new opportunities in a computer mediated learning environment for real time focus on form via synchronous corrective feedback (SCF) and negotiation of meaning, a key aspect of collaborative writing. In this review section, I'll explore the potential of this software in terms of synchronous feedback, collaborative writing, the process of writing and also recent studies specifically into the effect and experiences of students' use of google docs.

\section{A. Using Google Docs}

Google Docs includes all of the benefits of traditional word processing software. It allows for greater experimentation as it is easy to rewrite and it allows for discussion on language use as output is permanent and static. When used in with Google Drive TM it is easy to share and give access to documents which can be edited by multiple authors at the same time. As well as the collaborative opportunities, this gives, the teacher can also monitor the writing process as it occurs. It's possible to leave comments to the side of the main text, which allows for remote, synchronous real time written feedback.

Students find using Google Docs beneficial and like using it. Reference [3] showed that of students receiving SCF during writing tasks, the most positive impressions came when using online simultaneous editing software, later, Reference [4] backed up these findings showing that students responded well to teacher led feedback to make accurate revisions. This study also showed that students were able to participate actively in collaborative tasks while responding to the teacher's SCF. Other research into SCF by authors such as ref [5] and [6] suggests that focus on form does not necessarily detract from communicative activities.

When considering using a new tool with students, I normally consider the issue of learner training being a barrier. When I personally started to use Google Docs however, I was struck by how easy it is to pick up. It is very similar to the word processors I am used to, and sharing the document is made very easy by the teacher sharing permissions and sending simple links to the student. A study by ref [7] looking at collaborative writing using google docs outside of the classroom, found that although most of the students had not used google docs before the study, 93\% found it useful for group work. Because of this and my own experience, I believe there won't be much of a barrier in using Google Docs, especially with this particular student who is an IT professional.

\section{B. Synchronous vs Asynchronous Feedback}

Reference [2] identified three characteristics of using SCF with google docs which do not occur when employing ACF. The first was a difference in writing process. She observed a cycle of internalisation of input, modification of written output and consolidation by using the improved structure later in the text which continued until the writing was finished. The second showed that this process led to a gradual shift from teacher correction to self-correction. The third showed that the student was able to focus on both form and meaning during the writing task. These are linked directly to my aims for my student and suggest that google docs offers a new kind of learning opportunity for writing in one to one online classes. Shintani's study did focus on this feedback being provided in written form as Google Docs allows for written comments in real time. How to Think in another Language without Translating In slight contrast, I plan to use SKYPE video chat at the same time as the writing task which should make it easier for the student to query feedback.

One recent study by ref [2] found that using synchronous corrective feedback improved students' accuracy in posttests as compared with a comparison group that only received ACF. They observed that new software such as google docs TM and Microsoft's Skydrive TM allow what is a relatively new opportunity for SCF both practically in classroom pedagogy and in terms of SLA. The authors also mention the key benefit of receiving gradual scaffolding, in line with socio cultural theory.

For me, this kind of programme is the first time I've had access to practical resource which allows for SCF while teaching a distance student online. Other programmes such as Wiki's or word documents in shared file tend to only allow for one editor at a time, or in the case of word processors, can only be shared by sending the file email or Dropbox and so on. Although these studies focussed on corrective feedback, I will be employing more than one 
method of feedback and awareness raising during my classes.

\section{Writing Processes and SCF}

When writing, it is generally held that there are three major processes which occur simultaneously. These are; planning which includes goal setting, generating and organising ideas, translating which includes formulating and producing texts and text revision which includes comparing the produced text with a mental representation of an 'ideal text' and then altering the text accordingly [8]. Reference [2] identify that it is the revision stage which is most relevant to SCF. These three processes are affected by 'learner external factors', and learner internal factors such as working memory. SCF has the potential to increase cognitive load and impair the planning and translating processes. If this is true, SCF may actually harm the writing process. However, as writing is a slow-paced activity, there is the chance to separate revision from planning and translation through prioritising which aspect to focus on at any one given moment. This allows learners to reduce cognitive load by separating focus on different processes like evaluating accuracy and planning and translating their message. Reference [9] noted that learners tended to respond to SCF given while composing a sentence after completing the sentence. This implies that if there is enough time for revision, then this separation is possible and such feedback can be beneficial.

There are several other benefits of using SCF in relation to the writing processes. Reference [10] relates some of the written output and that it is permanent, unlike oral output. This can help noticing and repair and lead to knowledge consolidation. Reference [11] argues that SCF helps formfunction mapping because it gives necessary information about language while the learner is focussed on their message. Reference [9] adds, that in comparison to ACF, SCF has the advantage of providing context for the same reason. This may also result in greater motivation and focus on the quality of the written message.

SCF also has the advantage of allowing the teacher to scaffold the learners writing development during the production of the text. According to the social construction perspective, this leads to greater accuracy on the final text produced and greater development [12]. I will cover this more fully in the next section.

Reference [2] found that SCF delivered using an online editing programme improved accuracy in future similar writing tasks, helped learners significantly on developing explicit knowledge and also had a longer lasting effect than $\mathrm{ACF}$. This is attributed to the fact that SCF was "the opportunity for improving accuracy in the process of composing their texts", allowing students to make use of it during planning and translating. This is not possible with ACF. One case in particular showed that a student receiving ACF struggled to apply it in future writing in contrast to a student receiving SCF who "had more opportunities for composing correct hypothetical sentences while they were completing the writing task" as the corrections were produced shortly after feedback and this could be referred back to while planning future sentences in the same text. unique qualities of writing output, namely that there is more time to monitor

\section{Cognitive and Social Processes: Collaborative writing}

Sociocultural thinking [13] put forward the theory that human development is a socially situated activity. In this model, less able language learners' knowledge is constructed through collaboration with more knowledgeable others (MKO) who provide assistance known as 'scaffolding'. Based on this, collaborative learning, using pair and group work has become common and central to many ESL classrooms today. Collaborative writing falls under this umbrella and there is plenty of research that supports the benefits of collaborative writing. In one such study, ref [14] analysed interactions between learners during collaborative writing tasks and found that there were many examples of what she terms 'language related episodes' (LRE). This confirmed that these tasks "Served to create opportunities for learners to question their language use, test and confirm hypotheses, offer and assess new input, and provide both positive and negative feedback." Her overall conclusions showed that pair work provided more LREs and focus on language, this effect was improved even more in groups of more than two, an opportunity not available to me in my context. Reference [15] argues that pair work has the benefit of ensuring that the students actually contribute which may not happen in larger groups. In my case the student must contribute as it is a one to one class. The fact that sometimes LREs were resolved incorrectly as none of the learners had the knowledge may mean that the teacher to student interaction I am required to use may be a benefit, as this should not occur with a native speaker as the MKO.

The varied nature of the discussion and negotiation opportunities which the students took advantage of during the LREs show that it is not only SCF which is useful when co constructing knowledge during a collaborative writing task. Reference [5] lists useful implicit and explicit interactional devices which can be used during a task including, requests for clarification, recasts, explicit correction, metalingual comments/questions, queries and advice. These can be used in student to student or teacher to student interactions.

In my own situation, I am teaching one to one which has implications for my role during the task, order to gain the benefits of collaborative writing, I will need to position myself as a collaborator, not a teacher, but still use my position as the MKO to scaffold my student's development. To achieve this, I'll give up content control to the student, where possible offer alternatives for my student to consider before direct correction and lead a review of the final product. In future classes I would like to employ similar strategies with online group work. 


\section{TEACHING PLAN}

Using the ideas discussed in the literature, I developed a lesson plan which allows me to combine the use of a Google Doc with SKYPE to utilise a collaborative dialogue writing task with my one to one student. To recap,the key affordances offered by the software were the ability to share and co edit the document in real time while holding a video chat on SKYPE. This collaboration allows for enhanced knowledge construction through scaffolding and SCF, which can help overall L2 development, and more accurate written output. The latter remains as a record for review after the class is finished.

The class is run via video chat on SKYPE or a similar programme. Before running the class, the teacher needs to make sure the student has a google account so that they access the google doc which should have been created and shared via a link before the class begins.

As discussed, I use the dialogue building activity as one stage of a one hour class to focus on language use and build language knowledge before attempting a final speaking task. During the collaborative writing task, the teacher takes the role of a collaborator and stretches the student's language use though raising awareness of errors, opportunities and giving input of ideas. Suggestions and input can be given through conversation or using the comments function.

I use the same lesson structure, but introduce different language aspects in each lesson which means the student must alter the dialogue accordingly, focussing on appropriate meaning, use and form of language.

After developing the plan, I ran these classes with the student. As anticipated, there were no issues with sharing, accessibility or needing to train the student how to use the software. The results were excellent in both the short and mid-term and over the following weeks. We repeated this dialogue building exercise once a week for three weeks. Over the three weeks the student clearly improved his accuracy and made many fewer lapses on previously common language errors. It was noticeable that he needed less and less corrective input from me and took more control of self-correction and also began to revise the final dialogue by reviewing the content and questioning aspects of the language without prompting. This was consistent with the findings from ref [2]. An interesting point was that he started to use prior knowledge of English to ask relatively complex questions over the nuances of meaning in certain phrases in context. This suggests that something about the process activated his previously learned knowledge. The student also displayed more appropriate choices and a greater range of language use during the speaking task each week. This supports the notion that writing can indeed help SLA development beyond writing skills. The fact that I had previously run SCF during conversation to less effect is also interesting.

\section{FUTURE CONSIDERATIONS}

Firstly, in order to support my subjective experience of the benefits of using google docs in this way, I'll need to run a more empirical study. As the classes are recorded, it would be possible for me to transcribe both the conversations which happened during the collaborative writing and the speaking tasks. This would allow for a more rigorous analysis.

There are a number of other areas to consider when using collaborative writing activities. These include task design, social affective variables and competency of the student. Although my own task using Google Docs, was largely successful in the short term, this was only with one adult, high level student with good motivation and excellent IT skills. A larger study into these areas would be informative and useful in the practical application of online simultaneous editing software in collaborative writing.

Another important ongoing discussion is the role of corrective feedback in SLA. In this assignment, I have focussed on how to use Google Docs TM to provide both feedback and error correction only in terms of the opportunity to do this synchronously in a computer mediated class and how this aids focus on form during a task through collaborative writing. It will be important to look at the effect of different strategies for focus on form in future studies.

\section{References}

[1] G. Wigglesworth, What role for collaboration in writing and writing feedback. Journal of Second Language Writing, 21, 364-37, 2012.

[2] N. Shintani, N, and S. Aubrey, "The Effectiveness of Synchronous and Asynchronous Written Corrective Feedback on Grammatical Accuracy in a Computer-Mediated Environment". The Modern Language Journal 100, 1, pp.296-319, 2016

[3] S. Kim, S. Revising the revision process with Google Docs. In S Kasten (Ed.), TESOL classroom practice series. Effective second language writing, pp. 171-177. Alexandria, VA: TESOL Publications, 2010.

[4] S. Aubrey, Students' attitudes towards the use of an online editing program in an EAP course. Annual Research Review, 17, pp. 45-57, 2014.

[5] R. Ellis, Task-based language learning and teaching. Oxford: Clarendon Press, 2003.

[6] J.A. Willis, A Framework for Task-based Learning. London: Longman, 1996.

[7] W. Zhou, E. Simpson, and D. Domizi, Google Docs in an Out-ofClass Collaborative Writing Activity. International Journal of Teaching and Learning in Higher Education, vol. 24, pp. 359-375, 2012.

[8] L.S. Flower, and J.R. Hayes, "The dynamics of composing: Making plans and juggling constraints". In L. W. Gregg \& E. R. Steinberg (Eds.), Cognitive processes in writing, pp. 31-50. Hillsdale, NJ: Lawrence Erlbaum, 1980.

[9] N. Shintani, The effects of computer-mediated synchronous and asynchronous direct corrective feedback on writing: A case study, 2015.

[10] J. Williams, The potential role(s) of writing in second language development. Journal of Second Language Writing, 21, pp. 321-331, 2012. 
[11] M. H. Long, Problems in SLA. Mahwah, NJ: Lawrence Erlbaum, 2007.

[12] A.L.I. Aljaafreh, and J.P. Lantolf, Negative feedback as regulation and second language learning in the Zone of Proximal Development. Modern Language Journal, 78, pp. 465-483, 1994.

[13] L.S. Vygotsky, Mind in society: The development of higher psychological processes. Cambridge, MA: Harvard University Press, 1978.

[14] Dobao, A. F., 2012. Collaborative writing tasks in the L2 classroom: Comparing group, pair and individual work. Journal of Second Language Writing, 21, pp.40-58.

[15] M. Swain, Integrating Language and Content Teaching through Collaborative Tasks, 2001. 